\title{
The first description of tropical sprue ${ }^{1}$
}

\author{
C. C. BOOTH \\ From the Department of Medicine, Postgraduate Medical School of London
}

Until relatively recently the term 'intestinal malabsorption syndrome' has enshrouded our ignorance of a wide variety of disorders which may interfere with absorption. Some of these, coeliac disease for instance, were first clearly described nearly a century ago (Gee, 1888). Others, such as some of the absorption defects due to pancreatic disease, have only been recognized in the last 30 years (Anderson, 1938). The term 'sprue' has often been used as a synonym for 'intestinal malabsorption' and this has led to considerable confusion in the literature. The credit for the first description of sprue is usually given to Kaetelaer, who gave an account of what might possibly have been an adult form of coeliac disease in Holland in 1669 (Kaetelaer, 1669). The clinical syndrome which is known as tropical sprue is quite different from any of the diseases of temperate climates. Tropical sprue is a particular form of intestinal malabsorption, probably of infective origin, that occurs in tropical parts of the world. It has a very curious geographical distribution. It occurs all over the Far East, but no certain case has hitherto been described from Africa. It also occurs in the West Indian Islands of Barbados and Puerto Rica, but has never been seen in Jamaica (Manson Bahr, 1954). When it occurs it is usually endemic and liable to sporadic epidemics. The primary pathology lies in the intestinal mucosa; this shows histological abnormalities (Butterworth and Perez Santiago, 1957) which are readily recognized when biopsy material is examined under a dissecting microscope (Fig. 1).

The first clear description of tropical sprue was given by Dr. William Hillary over 200 years ago, and it was in Barbados that he described it. Since this year is the 200th anniversary of Hillary's death, it seems fitting that gastroenterologists should remind themselves of the clinical description which has earned him an assured place in medical history.

Hillary was not in any position to define the geographical distribution of tropical sprue, although this is implied in his statement that he had never seen it in England. But he did note its epidemic nature in Barbados. 'After I came there in 1747' he ${ }^{1} \mathrm{~A}$ paper read to the Osler Club of London on 24 January, 1963. wrote, 'I did but see one Person who had it, in the first four Years of my residing there; and three more in the next three Years: But within the four last Years past, it is become so frequent that $I$ have seen some Scores of Patients labouring under it ...' His description of the disease, which he called the Aphthoides Chronica, follows:

'The patient who labours under this Disease, usually first complains of an uneasy Sensation, or slight burning Heart about the Cardia, or upper Mouth of the Stomach; which comes slowly on, and gradually increases, and rises up in the Oesophagus into the Mouth, without any Fever, or the least feverish Heat, or much Pain attending it; most commonly without any observable Intemperance or Irregularity of living, or without any surfeit, taking Cold, or any sort of Fever or other Disorder, which it can be attributed to, preceding it, or any manifest or immediate Cause to which it can be ascribed.

'Soon after this burning Heat, little small Pustulae, or Pimples, filled with a clear, acrid Lymph, no bigger than a Pin's Head, begin to rise; generally first on the End and Sides of the Tongue, which gradually increase in Number, not in Magnitude, and slowly spread under the Tongue, and sometimes to the Palate and Roof of the Mouth, and the inside of the Lips; and soon after this the skin which covers those Pustulae, slips off, and the Tongue looks red and a little inflamed, though not swelled, yet is almost raw like a Piece of raw Flesh, and is so tender and sore, that the Patient can eat no Food but what is soft and smooth, nor drink anything that is vinous or the least spirituous, or the least pungent, without acute pain; So that some suffer much from the want of proper Food ...

'In this State they continue several Days, or Weeks, and sometimes for Months, sometimes a little better, then worse again; and after a considerable time, sometimes longer, and sometimes shorter, the Pustulae will disappear and the Mouth grow well, without any Medicines or Applications, or any manifest Cause, and continue so far for several Days or weeks ...

'This generally continues but a little time before a Diarrhoea comes on, and continues a longer or 

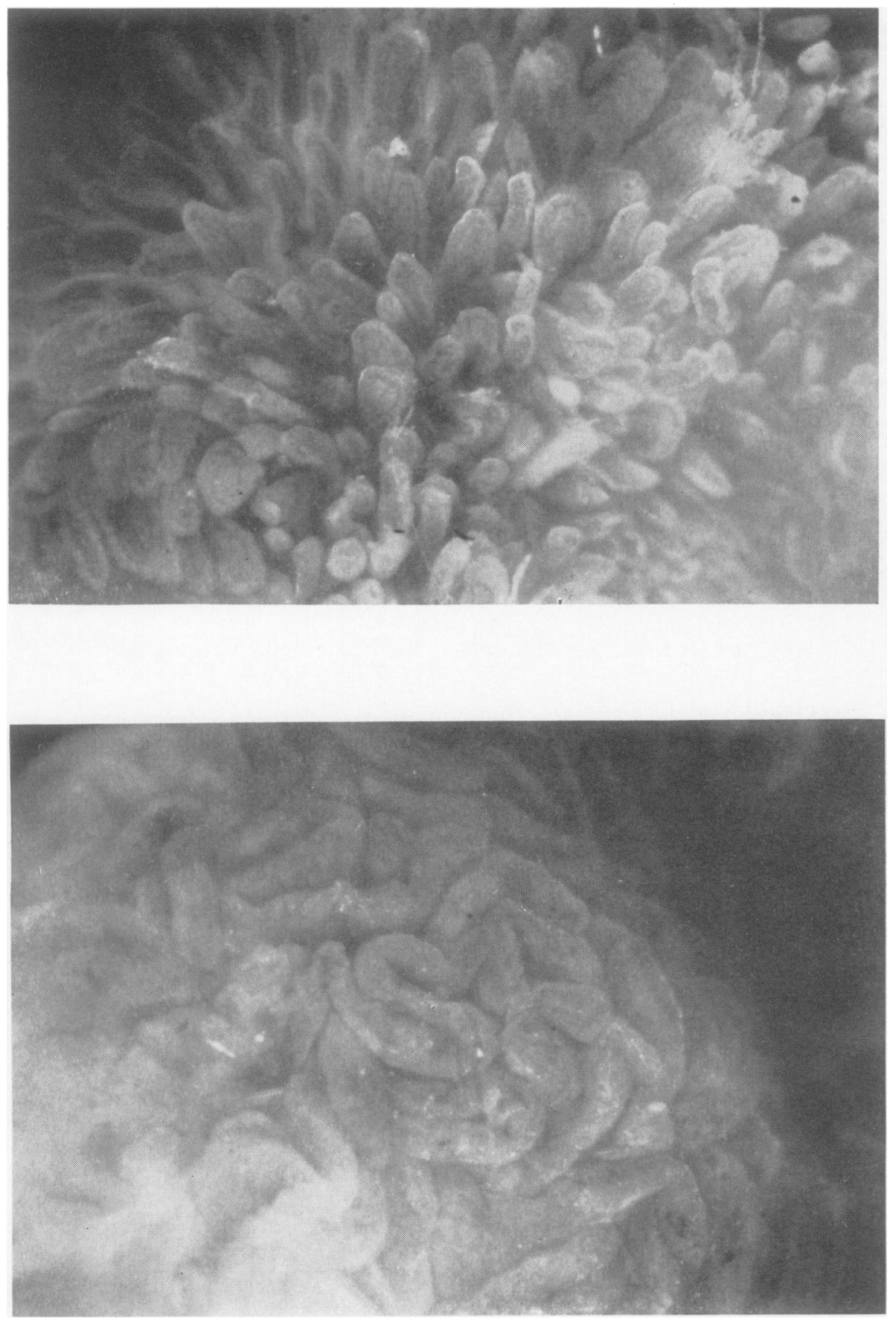

FIG. 1. The upper figure shows the appearance of normal jejunal mucosa viewed under a dissecting microscope; the lower figure illustrates the convoluted appearance of the mucosa in a case of tropical sprue $(\times 32)$. 
shorter time in different Patients, and sometimes for a longer or shorter time in the same Person, and in some it continues for many Weeks; and in all it greatly wastes their Flesh and Strength, and sinks their Spirits very much. The Diarrhoea after continueing a longer or shorter Time, sometimes stops without taking any Medicines, or doing anything to stay it, and the Patient thinks himself better for a short Time, and sometimes for a longer time; but in general the acrid Humour soon returns to the Mouth again, with all the same Symptoms, but somewhat increased or agravated; and after some stay there it removes from thence to the Stomach and Bowels again ...

'The Patients are all doing without any Fever or feverish Heat, and their Pulse is all this Time rather smaller, lower, slower and more languid than it was when they were in full Health; and their Body and Countenance rather paler... than when they were well ...

'And when the Humour falls upon the Intestines, it produces a Diarrhoea with a sense of Heat, and sometimes a griping (tho' the last not often), and sometimes with hot stools and a Tenesmus; so that most of the nutritious Juices run off that way, which greatly wastes and sinks the Patient. These Circumstances continueing, and the Disease frequently changing from place to place, almost continually deprives the Sick of their proper Nourishment, whence a true atrophy is produced, which at the last, either sinks the Patient or brings on a Marasmus, which soon ends in Death' (Hillary, 1759).

In this excellent description, Hillary emphasized the cardinal clinical features of tropical sprue: the chronic nature of the disease, subject to relapse and remissions, the troublesome glossitis, now known to be due to folic acid deficiency, the recurrent diarrhoea, which as he states, gradually wastes the patient, depriving him of his nourishment, leading to anaemia, progressive wasting, and death.

Hillary has not been credited by some writers (Major, 1939; Bockus, 1946) with the first description of sprue. As already stated this is because until recent years the tropical form of sprue has often been confused with its non-tropical counterpart, coeliac disease. Kaetelaer's description may possibly be of this latter condition but his observations were obscure and uncertain and bear no relation to the purely tropical condition that Hillary saw in Barbados. Hillary's description is authoritative and complete. He had clearly watched and recorded at the bedside of many of his patients; and he no doubt remained as puzzled as to aetiology as the physician of today. The first edition of Hillary's book on the Diseases of Barbados, in which his account was published in 1759 , is rare today and the second

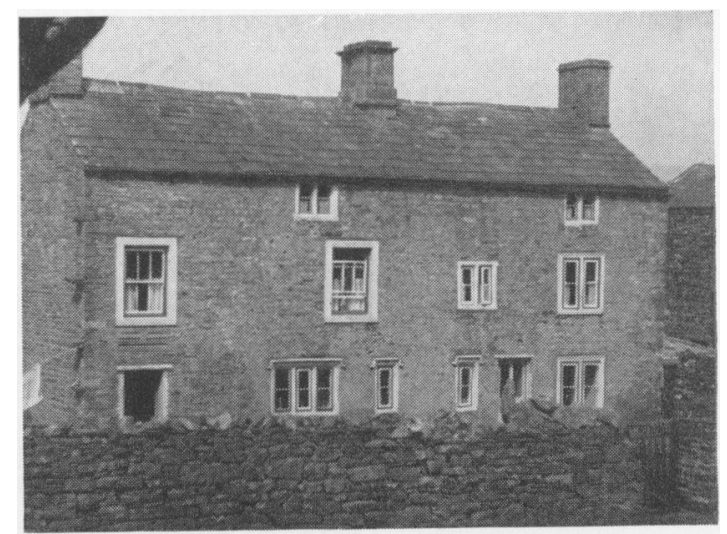

FIG. 2. Hillary Hall, in the village of Burtersett in Wensleydale.

edition, published in 1766 , is often quoted as the date of his description, an unfortunate error since by then he had been dead for three years (Hillary, 1766; Garrison, 1929).

Who was this English physician who gave so clear an account of this tropical disease? What was he doing in the remote island of Barbados? And how did he come to give us so excellent an account of sprue? He was in fact a product of the University of Leyden, graduating in 1722, one of Boerhaave's most able pupils. Boerhaave was an enthusiastic protagonist of Sydenham's method of careful bedside clinical observation and it is likely that the careful bedside observations Hillary made in Barbados owe a great deal to the training and encouragement he received from Boerhaave in Leyden.

William Hillary was a Yorkshireman and a Quaker. He was born in March 1697 in an isolated farmhouse called Birkrigg which is right at the top of the valley of Wensleydale. He only lived two years here, and from 1699 onwards was brought up in a village a few miles down the dale, Burtersett, where the home of the Hillarys is known as Hillary Hall to this day (Fig. 2). He left here in 1715 to become apprenticed to Benjamin Bartlett, an apothecary in Bradford, and then in 1720 or thereabouts went on to take his degree at Leyden. His thesis, entitled 'Dissertatio medicas inauguralis practica de Febribus Intermittentibus' is dated 24 July 1722 (Hillary, 1722).

He settled in practice in Ripon in Yorkshire in 1723 or 24 and lived there for over 10 years. Those years produced a book on the smallpox, published in 1735, which is of no particular significance apart from the price it fetches in twentieth-century bookshops. But there is one passage in the Preface which 
outlines the scientific idealism which Hillary brought to his work:

'It appears how necessary it is for a Physician who would be Successful in his Practice, or make any tolerable Figure in his Profession, to be well acquainted with the structure of the Human Body, the use of all its Parts, the Principles of Mechanical Powers, the Laws of Motion and Hydraulics, with a sufficient skill in geometry and Mathematics, to apply them; as well as a knowledge of Chymistry, Pharmacy, and the Virtues and Doses of Medicines. For it is by a proper Use and Application of these, both in our Practice and Reading, that we can account for the Causes and Effects of Diseases, and the manner of the Remedies acting, so as to produce their saluterious effects. It is by these and accurate observations in Practice, that we must improve our Knowledge in the State of Physic and Diseases, it is this Knowledge, and these Abilitys, that must be the distinguishing Characteristic of a true Physician, from an Empiric; it is by this method of reasoning from Data, founded upon Observations and real facts, that the Healing Art must be improved and brought to a State of Perfection; for if we once quit our Reason for Mystery, and abandon a just Method of Mechanical and Geometrical Reasoning, for the unintelligible terms of Occult Faculties and Qualities, with all such like Metaphysical and Chymical Jargon and Nonsense, heretofore too much used in the Schools; we must wander through endless Mazes, and dark Labyrinths, playing at Hazard with Men's Lives, and suffer ourselves to ramble wherever conceited Imagination, or whymsical Hypothesis will lead us'. (Hillary, 1735).

These words are written in the forthright language characteristic of a Yorkshire dalesman, but the ideas clearly derive from Boerhaave's teaching at Leyden. They illustrate the philosophy of medicine that was to activate Hillary throughout his life.

Hillary left Ripon in 1734. He was tired of country practice and decided he would try his hand as a fashionable physician. He moved to Bath, then at the height of its fame. The Pump Room and the Assembly Halls were thronged with the cream of English society enjoying the delights of taking the waters, conversation, music, dancing, the theatre, and the pleasure of being seen in the company of some of the most distinguished people in the land. The leading physician was Dr. William Oliver, later to be remembered for his Bath-Oliver biscuit. Over all presided that social genius, Beau Nash, the arbiter of elegance, dictator of the manners of polite society.

It was to be a very different world from Ripon. No doubt Hillary started his practice among the members of the Society of Friends. But in 1737, he discovered that a spring in the valley of Lincomb, a little to the south of Bath, was a mineral water and his next few years were spent exploiting the virtues of this water, which he considered superior to the waters of Bath (Hillary, 1742). Unfortunately, his activities may have incurred the enmity of powerful colleagues in Bath. What happened will never now be known but history does record that Hillary was preparing to leave Bath in 1746. In the autumn of that year he was in London exploring the possibility of becoming a physician in Jamaica. His situation in Bath was described by a friend as 'not the most agreeable nor the prospect very pleasant'. The friend was John Fothergill, then in the early years of his practice in London, writing to his brother Alexander in Wensleydale, Yorkshire, a neighbour of Dr. Hillary's elder brother Isaac. 'Whilst he was here' Fothergill wrote, 'news came of the Death of the only eminent Physician in Barbados: I procured him an interview with a person who gave him an exact account of the affairs of that Island; he likewise spoke with many others who jointly recommended the place as much preferable to Jamaica ...' (Fothergill, 1746). Hillary decided to take the Barbados post. It was one of those intriguing turns of the wheel of fortune. Had he gone to Jamaica he would never have seen a case of tropical sprue.

He must have travelled to Barbados in the spring or early summer of 1747 . No doubt he was disappointed that he had failed in Bath. In fact, it was the most important step in his life. Had he stayed in Bath, dosing the chronic sick with the waters, he would perhaps have made a fortune but he would have made little contribution to the medicine of his day. Whilst in fashionable Bath, Hillary had given up his practice, started in Ripon, of observing the changes in the weather and the related epidemic diseases. Working entirely on his own in Barbados, he would take up this practice again and obtain data 'founded upon observations and real Facts' which would be of lasting value. He would never have had such opportunities in the conventional society world of Bath.

Nothing is known of Hillary's day-to-day work during his early years in Bridgetown. But one visitor to Barbados has left an account of a professional visit from Dr. Hillary in 1751. The writer was a young Virginian, aged 19 years, who had brought his elder brother to Barbados for his health. The elder brother had developed ominous signs of consumption and had been ordered to spend the winter in a warmer climate than Virginia. They arrived in Bridgetown on 3 November, where they met Major Clarke, commander of James Fort and of the British Forces in the Windward Islands. The writer recorded in his diary for 5 November, 1751: 
'Early this morning came Dr. Hillary, an eminent physician recommended by Major Clarke, to pass his opinion on my brother's disorder, which he did in a favourable light, giving great assurance, that it was not so fixed but that a cure might be effectively made. In the cool of the evening we rode out accompanied by Mr. Carter to seek lodgings in the country, as the Doctor advised, and were perfectly enraptured with the beautiful prospects, which every side presented to our view.-The fields of cane, corn, fruit trees, all in a delightful green' (Toner, 1892).

The patient referred to in this passage was none other than Lawrence Washington, of Mount Vernon in Virginia, and the young diarist was his stepbrother, George Washington, inheritor of Mount Vernon, Commander of the Armies of the American Colonies in the War of Independence, first President of the United States of America. Dr. Hillary's favourable prognosis is at first difficult to reconcile with his patient's subsequent progress. Lawrence spent three months in Barbados, then went to Bermuda. He arrived home in Virginia in the following June, a shadow of his former self, and died on 24 July 1752 . But the modern physician would approve Hillary's cheerful approach. He must have been familiar with pulmonary tuberculosis, must have himself known what the prognosis might be. Yet no physician will readily leave his patient without hope, whose therapeutic effects are mysteriously effective, and there is therefore much to commend Hillary's encouragement.

The Washington brothers stayed in Barbados with Captain Crofton at Fort James. Here, George fell ill with smallpox and from 17 November until 12 December was under the care of a Dr. Lanahan. He does not record whether Hillary, whose book on the smallpox would make him an expert on this disease, was called in. The attack was fortunately mild and George Washington came through relatively unscathed, having achieved an immunity to the disease which was no doubt valuable in later years (Toner, 1892).

In 1759, the Annus Mirabilis of the Seven Years War, Hillary came home to London and retirement. He wrote another book soon afterwards which is of interest to the medical historian, for it is no less than an eighteenth-century history of medicine (Hillary, 1761). Two sections selected from this book, written at the end of his life, illustrate first his respect for scientific logic, and second his regard for Boerhaave. $\mathrm{He}$ paid tremendous tribute to the importance of 'Francis Bacon, Lord Verulam', who, he said, was 'one of the greatest Genius that any Age ever produced; and although he was not a Physician, but a Lawyer and a Philosopher, yet he first discovered and taught Mankind the right way of Thinking, and the true method of discovering Truth, and obtaining true Knowledge and Certainty, both in Philosophy and in Physick, and all other Sciences.' He stressed his indebtedness to Boerhaave in the following passage. Boerhaave, he says 'was blessed with great Penetration, a sane Judgment, and the strongest Memory; all of which he early applied with indefatigable Industry, to obtain a perfect knowledge of all the learned, and many of the modern Languages, and all the Sciences; an able Philosopher, the greatest Anatomist, Chemist, Botanist and the most eminent Physician of this, or any other Age.' No teacher of medicine could wish for a more handsome tribute from a pupil.

Hillary died in April 1763, and the Gentleman's Magazine merely recorded the death of 'Dr. Hillary, well known for his many ingenious treatises on Physick.' These 'ingenious treatises' deserve the attention of all physicians who today seek to improve the practice of medicine by scientific methods. Hillary has a forthright style which is attractive to read. The clarity of his thinking, his careful clinical descriptions, his condemnation of bigotry and preconceived ideas are refreshing reminders of the scientific renaissance that began to influence clinical medicine in Britain in the eighteenth century. The most impressive feature of his work is the whole-hearted enthusiasm of his belief in the value of a scientific approach to medicine. Hillary's careful clinical description of tropical sprue was no accident, but achieved by the application of bedside clinical methods he had learnt at Leyden and practiced through his life. 'It is by this method of reasoning from Data, founded upon observations and real Facts, that the Healing Art must be improved and brought to a state of Perfection,' he had written in 1735 . Nearly 30 years later, the scientific idealism inculcated at Leyden by Boerhaave was in no way diminished.

I wish to thank Mrs. A. E. Wallis of Darlington for her kindness in sending me copies of her Fothergill correspondence; Mrs. B. C. Corner of Philadelphia for drawing my attention to the references to Dr. Hillary in George Washington's Barbados journal; and Edward Milligan, of the Library of the Society of Friends in London, for his help in consulting Quaker records.

\section{REFERENCES}

Anderson, D. H. (1938). Cystic fibrosis of the pancreas and its relation to coeliac Disease; clinical and pathological study. Amer. J. Dis. Child., 56, 344.

Bockus, H. L. (1946). Gastroenterology, vol. 2. p. 230. Saunders, London and Philadelphia.

Butterworth, C. E., and Perez Santiago, E. (1957). Pathological changes in jejunal biopsies from sprue patients. Amer. J. dig.
Dis., 2, 659 .

Fothergill, J. (1746). MS letter to Alexander Fothergill dated 11/7 1746. In the care of Mrs. A. E. Wallis of Darlington.

Garrison, F. H. (1929). An Introduction to the History of Medicine, p. 717. Saunders, London and Philadelphia. 
Gee, S. (1888). On coeliac affection. St. Barts. Hosp. Rep., 24, 17. Hillary, W. (1722). Dissertatio Medicas Inauguralis theoretica practica de Febribus intermittentibus. M. D. Thesis, Leyden University. (1735). A Rational and Mechanical Essay on the Smallpox. Strahan, London.

(1742). An Inquiry into the Contents and Medical virtues of Lincomb Spaw water near Bath. Leake, Bath, and Hitch, London.

-, (1759). Observations on the Changes of the Air and the concomitant Epidemical Diseases in the Island of Barbados, to which is added a Treatise on the putrid bilious Fever, commonly called the Yellow Fever; and such other Diseases as are indigenous or endemical, in the West India Islands. Hitch and Hawes, London.

- (1761). An Inquiry into the Means of improving Medical Knowledge, by examining all those methods which have hindered or Increased its Improvement in all past Ages. Hitch and Hawes, London.
, (1766). Observations on the Changes of the Air and the concomitant Epidemical Diseases in the Island of Barbados, to which is added a Treatise on the putrid bilious Fever, commonly called the Yellow Fever; and such other Diseases as are indigenous or endemical, in the West India Islands. Hawes, Clarke and Collins, London. 2nd edition.

Kaetelaer, V. (1669). Cited by Major, p. 657.

Major, R. H. (1939). Classic Descriptions of Disease, p. 659. Thomas, Springfield, Illinois.

Manson Bahr, P. H. (1954). Manson's Tropical Diseases, p. 543. Cassell, London.

Toner, J. M. (1892). The daily Journal of Major George Washington in 1751-2, kept while on a Tour from Virginia to the Island of Barbados, with his invalid Brother, Major Lawrence Washington, proprietor of Mount Vernon on the Potomac. Munsell's, Albany, N.Y. 